\title{
Reimagining academic staff governors' role in further education college governance
}

\section{Abdulla Sodiq \& Ian Abbott}

To cite this article: Abdulla Sodiq \& lan Abbott (2018) Reimagining academic staff governors' role in further education college governance, Research in Post-Compulsory Education, 23:1, 138-157, DOI: $10.1080 / 13596748.2018 .1421017$

To link to this article: https://doi.org/10.1080/13596748.2018.1421017

曲 Published online: 06 Mar 2018.

Submit your article to this journal $\widetilde{ }$

Џ Article views: 63

View Crossmark data \lceil 


\title{
Reimagining academic staff governors' role in further education college governance
}

\author{
Abdulla Sodiq (D) and lan Abbott \\ Centre for Education Studies, University of Warwick, Coventry, UK
}

\begin{abstract}
This paper aims to explore Academic Staff Governor (ASG) roles at three further education colleges in England. Uniquely, the research focuses on ASG activities, the understanding of ASG roles, and aspects of the role that can be reimagined, which may be of benefit to practising governors, particularly ASGs such as further education (FE) teacher governors. The study draws upon relevant literature to identify concepts related to governors' roles and activities. An interpretivist stance is used to collect predominantly qualitative data through a combined methods approach, and to engage with ASGs and external governors. During fieldwork, qualitative and quantitative evidence was analysed from semi-structured interviews, questionnaire responses, observations of governance meetings and governance documents. Findings suggest that ASGs' insiderness, their affiliation with other groups and decision-making circumstances may influence their governing activities. Activities rooted in operational settings such as professional-information giving were highly valued by other governors, while there were uncertainties about the benefit of having managerial staff as ASGs. There was evidence indicating uncertainty among the college staff regarding the role of an ASG in the colleges' boards. As a result of the study, to conceptualise an ASG's role in FE colleges, 'The 3 RaPs (Roles as Position/Perceived/Practice) Framework' for an ASG's role has been developed. The research recommends clear and specific role descriptions for ASG posts; action to allow more opportunities for ASGs to act as governors in order to transform the scope of the role. Finally, several recommendations are set out in order to address ASGs' insiderness, to promote ASGs' professional profiles in the FE sector and to improve the methodological approach for use in similar future research.
\end{abstract}

\section{ARTICLE HISTORY}

Received 1 May 2017

Accepted 1 August 2017

\section{KEYWORDS}

Academic staff governors; further education; governance; organisational roles

\section{Introduction}

At a time when research into further education (FE) College governance continues to be sparse, this paper presents the results of a study into Academic Staff 
Governor (ASG) roles in the governance of three colleges in England. All three colleges had been graded as 'Outstanding' in the most recent two inspections by the Office for Standards in Education, Children's Services and Skills (Ofsted) - the state's quality control authority. The research project conducted from 2011-2015 studied ASG role activities. It explored how well the role is understood within the colleges' governing bodies (corporation boards) and in what ways the role can be reimagined to give ASGs a fuller role in governance. The specific research questions were as follows:

(1) What are an ASG's general governance and ASG role-specific activities in the governance of the three colleges?

(2) What are the issues around the understanding of ASGs' role in the governance of the three colleges?

(3) In what ways can the role be reimagined to expand the role of ASGs?

Academic discussions in various education sectors outside FE and across geographical boundaries have highlighted the crucial role of academic staff in educational governance (MacNeill, Silcox, and Cavanagh 2003; Sallis 2006; Shattock 2002). However, recent changes at policy level in England arguably presented a worrying development for any teacher in FE who aspires to secure an ASG role in FE governance. The replacement of the reference to 'teaching' staff governors in the Education Act 2011 (HMSO 2011) with a generic reference using 'staff' governors means academics' place in FE governing boards is not guaranteed any more. Hence, there is a need to understand the roles ASGs currently play and to reconceptualise the role. Calls for reform in overall FE governance have already been made by Gleeson, Abbott, and Hill (2010). The current paper adds specificity to such calls by focusing on how the role of ASGs can be transformed and reimagined.

The current case study focussed upon three colleges (X, Y and Z) in England, and each of the governing body's composition is as shown in Table 1. Each had a single ASG, and the board's activities were co-ordinated by a Chair and within a number of committees, some of which the ASGs contributed to.

\section{Literature review}

\section{FE and educational governance}

At the time of the current project, published research into the role of ASGs in English FE colleges appeared to be non-existent. The author had to expand the literature search beyond $\mathrm{FE}$, to fields such as corporate governance and governance in schools, given the limited research in FE governance. School governance is explored because of a handful of highly pertinent, albeit dated, studies on teacher governor (TG) roles in schools (for example, Earley and Creese 2001); and corporate governance for the scholarly views on staff involvement in governance and 
Table 1. Composition of the corporations of the three colleges, $\mathrm{X}, \mathrm{Y}$ and $\mathrm{Z}$.

\begin{tabular}{lcccccc}
\hline College & $\begin{array}{c}\text { No. of gover- } \\
\text { nors }\end{array}$ & No. of ASGs & $\begin{array}{c}\text { No. of busi- } \\
\text { ness support } \\
\text { staff }\end{array}$ & $\begin{array}{c}\text { No. of } \\
\text { student } \\
\text { governors }\end{array}$ & $\begin{array}{c}\text { No. of } \\
\text { external } \\
\text { governors }\end{array}$ & $\begin{array}{c}\text { No. of com- } \\
\text { mittees }\end{array}$ \\
\hline $\mathrm{X}$ & 18 & 1 & 1 & 2 & 13 & 6 \\
$\mathrm{Y}$ & 15 & 1 & 0 & 2 & 11 & 5 \\
$\mathrm{Z}$ & 20 & 1 & 1 & 2 & 15 & 6 \\
\hline
\end{tabular}

board research. Using Fuller et al's (2013) definition, 'governance' in this study relates to structures and processes within the concerned FE colleges through which policies for the colleges' education are developed, implemented and reviewed. This study focusses on the Academic Staff Governors' involvement with such structures and processes within the governance of the three colleges.

The current study's main focus is on ASG's role and governing activities. Organisational 'role' is defined by Mullins (2004) as:

needed for analysis of behaviour in organisations. It explains the similar action of different people in similar situations within the organisation and the expectations held by other people. (Mullins 2004, 59)

The concept is given categorisation in Krantz and Maltz's (1997) ideas of formal/ informal roles; and in James et al's (2007) distinguishing concepts of 'roles-as-positions' and 'roles-as-practices'. Roles-as-positions are described formally in role descriptions and specifications. Roles-as-practices are the actual roles performed by governors as they understand based on their interpretations.

Following the work of several authors (for example, Hendry 2005; Zajac and Westphal 1996), van Ees, Gabrielsson, and Huse (2009) identified several useful concepts in a behavioural theory of corporation boards, which related to board members' activities and included the concepts of bounded rationality, satisficing behaviour and routinisation of decision-making (RoDM). The current study borrows these concepts for the purpose of studying ASG behaviour and what ASGs do in their governing roles. Bounded rationality, refers to the limited knowledge and potential incompetence of a governor in their role. Satisficing behaviour may apply to decision-making where a governor makes choices or forms judgements that are simply satisfactory instead of searching for optimal choices. Van Ees, Gabrielsson and Huse $(2009,312)$ describe RoDM as a past record or collection of 'successful solutions to problems that store and reproduce experientially acquired competencies, which can then be repeated over time' by the board.

With regard to research into ASGs and TGs contribution to institutional decision-making, Earley and Creese's (2001) governance study noted that the majority of school TGs did not have confidence in the governing boards' overall decision-making processes, for instance, in setting Senior Management Team's (SMT) pay; to some extent this could be linked to $22 \%$ of the TGs in the study being excluded from the decision-making process on such matters, perhaps, through 
routinised practices such as excluding them from meetings when pay-related matters are discussed.

One of the main rationales for including ASGs in a governing body may be to do with the ASGs' academic-related knowledge and experience. From the analysis of publicly available data on FE teachers' profiles (Clow 2005), one can hypothesise that in a given college it is likely that governor candidates among teachers may possess relevant professional educational knowledge and experience, and can enrich the pool of expertise within the college governing body. However, influential governance researchers like Carver and Carver (2013) and Brennan, Kirwan, and Redmond (2016) insist on governors being external to the relevant institution. Furthermore, in educational governance, there may be some apprehension about academic ASGs' expertise in non-pedagogic governance matters (New 1993b).

In terms of the governing arrangements in English FE, as of 2012, many colleges appeared to continue to use the 2007 version of the state-directed list of governor responsibilities despite a revamp of the responsibilities in the Education Act of 2011 (Table 2). Hill, Downs, and Drake (2012) inferred that the reason for the continuation of the state- directed instrument and articles of governance by the colleges was due to their measured adaptation of the changes in the 2011 Act. Following the new statutory Education Act (HMSO 2011), the AoC $(2013,37)$ recommended adding a further responsibility for an FE college board, which required each college to support 'the needs of the community(s) it serves'. Identification of such value-based responsibilities concurs with Stoker's (2004, 6) 'localism' approach, which strongly advocates colleges' direct interaction with local stakeholders through 'reason-giving, questioning and continuous exchange between the provider and the relevant public.' However, issues of how this is practised may exist (Lea 2005).

Hill, Downs, and Drake (2012) found that while $80 \%$ or more colleges had their corporation chairs' and principals' responsibilities defined, only $62 \%$ had the roles defined for other governors such as ASGs. Even where governance purpose and responsibilities were clear, for some governors in the case study by Gleeson,

Table 2. FE college governors' general responsibilities as of 2007 and the amendments in education act (2011).

\begin{tabular}{|c|c|c|}
\hline Governor responsibilities in DIUS (2007) & & Education act (2011) \\
\hline $\begin{array}{l}\text { Determination and review of ed. char- } \\
\text { acter, mission and oversight of college } \\
\text { activities }\end{array}$ & Condensed to & $\begin{array}{l}\text { Determination and review of educational } \\
\text { character and mission and oversight } \\
\text { of college }\end{array}$ \\
\hline Approving quality strategy & & $\begin{array}{l}\text { Effective/efficient use of resources, } \\
\text { solvency of institution and safeguard- } \\
\text { ing assets }\end{array}$ \\
\hline \multicolumn{3}{|l|}{$\begin{array}{l}\text { Effective, efficient use and safeguarding of } \\
\text { resources, solvency of college; }\end{array}$} \\
\hline \multicolumn{3}{|l|}{ Approving finances; } \\
\hline \multicolumn{3}{|l|}{$\begin{array}{l}\text { Appointment, grading, suspension, dis- } \\
\text { missal of SMT/staff }\end{array}$} \\
\hline Approving pay/conditions of SMT/staff & & \\
\hline
\end{tabular}


Abbott, and Hill (2010), the real issue in FE governance was, as also concurred by Cornforth and Edwards (1999), how to go about putting the responsibilities into practice, echoing Lea's (2005) concerns. Gleeson, Abbott, and Hill (2010) and Cornforth and Edwards (1998) expound that governors from various backgrounds may have different priorities, understandings and expectations of their role.

\section{ASGs' activities in educational governance}

In New's (1993a) study into teacher voice in school governance, the authors observed that TGs' contributions in meetings were limited and were categorised into several types, including the providing of 'professional information' and the presentation of staff viewpoints. Earley and Creese (2001) hypothesised that TGs may be interested only in matters of direct concerns to teachers, justifying a restricted professional model of TGs' participation in governance. This was supported in Lee's (2000) interviews with ASGs at four colleges in the Midlands. Earley and Creese (2001) found that TGs felt they were often excluded from the discussion of certain issues such as personnel, finance and salary matters. Such exclusion is evident in college boards too, as described in Lee's (2000) work in college governance. Both of the studies referred to the direct exclusion of ASGs, which may be by the Chair asking the ASGs/TGs to leave meetings because of potential conflict of interest in relation to the meeting agenda item, or indirect exclusion because ASGs/TGs felt intimidated to contribute to meetings due to the presence of their SMT in the meetings. In both of the studies, the exclusion could also be regarded as self-inflicted because staff appeared to take an interest only in matters that related to the general staff.

According to James et al. (2012), both supporting and challenging the management are aspects of good governance. However, governors may often back the SMT rather than providing the necessary constructive challenge because they may belong to the same peer group as the SMT (Mace 1973). In FE, ASGs may see the role's importance but some principals and governors may see the role as insignificant and ASGs' contribution as of little value (Lee 2000). Chapman, Collinson, and Collinson (2009) observed that governors (including ASGs) do not challenge the principals and Wilkins (2014) hypothesised the reason for this may be ASGs' affiliation with the SMT and that ASGs may find it difficult to make any meaningful contribution because decisions appear to be already made. Such empirical evidence, including research by Schofield, Matthews, and Shaw (2009), suggests that offering constructive challenge may be an area of concern in both school and FE governance in England, given that a 'vibrant ethos of challenge, self-criticism and self-improvement' is a 'critical success factor for effective governance' (Matthews, Snell, and Chapman 2011, 3).

Earley and Creese's (2001) findings showed that TGs were positive about governors who were involved with various school activities but that only 12 (5\% of) TGs visited their schools regularly as governors. ASGs may also be 'link governors' in 
boards. Gleeson, Abbott, and Hill (2009) defined a link governor as a 'dispassionate but interested individual' linked to a particular curriculum area under 'intensive care' because of its underperformance and that while such a governor may have limited knowledge of the curriculum area or of teaching, learning and assessment (TLA), he/she can help the college staff see things from a different perspective. Ofsted (2012a) reported that improving colleges may have link governors attached to all curriculum areas of the colleges.

\section{Role confusion}

A number of studies have revealed the confusion of ASG roles as a significant barrier in schools (Earley and Creese 2001; Taylor 1983). Cornforth and Edwards (1998), McNay (2002) and Lee (2000) found similar issues in FE governance. Hill (2012) advises that ASGs should participate in the collective responsibility of accomplishing the core functions stated in the college's instrument of governance using ASGs' knowledge of the college and its operational context. He believes 'accounting for how something works or doesn't work in college' $(2012,11)$ is not a governing activity and should consult the clerk when in doubt of the role. If boards follow LSIS (2012) advice that they should consult the general staff (as opposed to relying on the ASG) for staff perspectives on the college matters, then the pressure on ASGs to represent teachers may not arise, but it may restrict their role in governance.

\section{Research methods}

In the current multi-case study, more than one college was used in order to obtain sufficient data to provide insight into ASG roles. From Ofsted's (2012b) records of 'Outstanding' FE colleges in England, 16 potential FE colleges were identified. E-mails sent contained requests of official permission from the college corporation clerks for the colleges' participation in the research. The e-mails introduced the researcher and contained consent-specific information about the research project. Telephone conversations were held with the corporations' clerks and/or the college principals to provide an overview of the project for the colleges to consider. Three colleges accepted to take part in the research and were set as the number of case studies. Some of the reasons for the 13 colleges declining the invitation to participate included inappropriate timing due to staff SMT relations and lack of time due to other urgent matters such as Ofsted inspections.

A draft cross-sectional survey (Fogelman and Comber, 2007:127) questionnaire focusing on the research questions was designed to obtain data from the ASGs and other governors at the colleges. It was designed using online software, Qualtrics ${ }^{\circledast}$ (2002), and e-mailed to the governors via the clerks. The semi-structured nature of the questionnaire allowed the researcher to use respondents' own variables in the subsequent methods, adding to the reliability of the study. The questionnaire 
was based on comparable studies (Earley and Creese 2001; Gleeson, Abbott, and Hill 2010; Sodiq 2012) that had sought to collect perceptions of school and college governors.

The observation method was included in the study to address the first research question about ASG role-specific activities, to triangulate data (Bush 2007) and further explore emerging themes from the survey. The observation instrument (data and evidence collecting grid), containing space to record evidence from observed governance meetings, was used to collect information such as meeting attendees and layout of the meeting rooms, and ASGs' verbal contributions in meetings.

Six face-to-face semi-structured interviews were conducted, with an ASG and another governor from each college. The interviews focused on the emerging theoretical ASG concepts from the initial data analysis of the questionnaire responses and ASGs' contributions in the observed meetings. Once the first draft schedule was ready, it was used in the pilot study. The focus of the interview schedules for the ASGs was generally similar to the non-ASG interview schedules, but some specific questions allowed ASGs to make retrospective-meaning making (Patterson and Marshall 2014) of their own meeting contributions and governance experiences. The interview questions were broadly categorised into ASGs' governance activities and the understanding of ASG roles. During the interviews, a guide approach was followed but still allowing a degree of freedom for the interviewees.

The governance documents sought for analysis were lists of governors; Instruments and Articles of Governance; Standing Orders; Terms of Reference for observed committees; corporations' self-assessment reports; Ofsted inspection reports and agendas and minutes of observed and preceding/subsequent meetings.

\section{Findings and discussion}

\section{ASGs' general governance activities}

From the analysis of the evidence set, it appears that despite the presence of general specifications for role responsibilities for all governors, in practice what role the ASGs performed, roles-as-practices (James et al. 2007), was shaped by the ASGs' position as insiders and influenced by other insiders such as the SMT and the Chair of Governors. In this project, the 3 ASGs declared their behaviour of consulting SMT or the Chair of governors outside meetings. ASG at X-College said in the interview:

I would never do anything to deliberately embarrass the college, I would, as I have done before, I had gone to the Chair and said look, I've seen this in one of the governance papers. This is one of the questions that I want to ask, if it will cause embarrassment and she said no, you can ask that. (X-ASG; interview)

Similarly, Y-ASG (ASG at Y-College) confessed that he would 'go to the Principal's office and say 'what's going on?'; and Z-ASG thought it would be 'unfair' to confront SMTs at meetings, before him raising the relevant issue in person regarding 
difficult governance matters that needed querying. This observation is relevant to the issue raised by Carver and Carver (2013), where the authors express doubt about the benefits of including staff in governance to monitor their employers' performance, due to undue influence and conflict of interest.

It surfaced that ASGs may not have the space and support for performing some of the general governance roles that other governors may perform, for instance, contributing to staffing or remuneration discussions. At X-College, the instrument of governance barred ASGs from being involved in the remuneration committee. However, X-ASG confessed in the interview that in one of the corporation meetings, she had argued for a pay award for SMT at a time the public sector was experiencing financial difficulties because she believed the SMT was helping the college perform. Interestingly, the survey data across the three colleges showed that setting staffing pay and SMT pay were seen the least relevant activities for an ASG. In the questionnaire, in a spectrum of relevance from 0 to 5 identifying relevant governance activities for an ASG, reviewing the college's mission was ranked by governors across the three colleges at 4.4 out of 5 , while staffing pay was ranked at only 2.2 and SMT pay and conditions at just 1.9. This suggested that the governors did not believe it was necessary for ASGs to get involved in pay-related decision-making processes. A common argument for such exclusion, featured in the interview with the Vice-Chair, is that such an approach is adopted to protect ASGs from being put in a difficult position. However, it is possible to contest this argument with the view that ASGs' opinion may be a significant resource even in discussion of financial matters because of their understanding of education matters and the close link between finance and other resources, and TLA - a point highlighted by Z-ASG and the curriculum committee chair at X-College. Across the three colleges, all three ASGs were barred or discouraged from participating in the boards' remuneration committees, which meant they could not influence staff and SMT's pay and conditions significantly. This was in line with Masunga's (2014) finding in FE colleges.

Further analysis of interview data suggested that some governance decision-making may by-pass whole boards as found in $\mathrm{X}$ and $\mathrm{Y}$ colleges affecting ASGs' roles-as-practices (James et al. 2007). At one of the colleges, the ASG described how, in an annual strategy meeting, the SMT manoeuvred the agenda away from the governors' recommendations to favour SMT's pre-emptive decision-making. At another college, the ASG was frustrated how one SMT left the college without the board's knowledge and a college restructure that had taken place without any discussion at governance level. In these situations, it was difficult to see how the board, let alone the ASG, could contribute meaningfully to governance.

There were some examples where ASGs were seen to make an impact. ASGs' identification with their local communities encouraged ASGs to engage with local community issues. For instance, X-ASG being a member of the local community raised concerns about the impact of the college's academy building projects on 
locals and schools in the area. At Y-College, Y-ASG as a member of the ethnic community was observed in a meeting taking a lead role in promoting the college among the ethnic community. Similarly, Z-ASG raised the issue of mental health issues among young people in the community and pressed the Principal to make attempts to identify students with mental health issues at enrolment point so that early support could be provided. These instances of community-related contributions for the ASGs reflected a 'localism' approach to FE governance argued for by Stoker $(2004,6)$. They also present a multi-dimentional aspect of ASGs' roles, where their educational expertise and experience interact with their other interests and passion to contribute to governance - an approach that the current paper argues for in a reimagined ASG role in FE governance. However, the concept of bounded rationality in decision-making (van Ees, Gabrielsson, and Huse 2009; Hendry 2005) could hinder such efforts. Bounded rationality is the idea that in practice governors may not have enough resources to make the optimum decisions. In the real world, resources such as time and knowledge may not always be sufficient affecting governance of institutions. For instance, at X-College, in the board self-assessment processes for two consecutive years (2012/2013 and $2013 / 2014$ ), governors raised the issue of not knowing how to go about meeting the needs of the community.

A finding drawn from the analysis of the 3 ASGs' contributions in their governance meetings was that, overall, their contributions tended to be in support of SMTs' positions or decisions, rather than challenging SMT. Across the three colleges, 38\% (16) of meeting contributions supported SMTs' inputs. This was twice the number of challenges $(19 \% ; 8)$. All of the ASGs' supporting contributions were from the ASGs at X and Y colleges and none came from the ASG at Z-College. At the same time, Z-ASG's total contributions to meetings were significantly fewer compared with the other two ASGs. X-ASG was seen to comment/ask questions in 27 instances in three meetings and Y-ASG in 11 instances in three meetings. In contrast, Z-ASG made only four contributions in two meetings, one of which was his challenge to the principal regarding mental health screening of students at enrolment, described earlier.

$\mathrm{X}$-ASG's supportive contributions included nodding in an open and visible manner when the SMTs were delivering their reports on various governance topics. In the interview she explained such non-verbal gestures were to show the rest of the governors that she was in agreement with the SMTs' reports and give her backing to some of the points they were making. Her challenges included her questioning the strength of the audit reports' claims that IT audit results were communicated to the curriculum areas because in her experience, this was not the case in practice.Y-ASGs' supportive comments included him supporting the principal's assertion to the governors that there were robust systems in place to support underperforming teachers. His single challenge put forward was directed at the Principal discussing the public dissemination of marketing information with performance statistics showing the college's recent achievements nationally - an 
action both the Principal and Y-ASG supported. Nevertheless, Y-ASG gently challenged the Principal and emphasised how the marketing information would entice members of the local community into considering the college for their education:

Y-ASG: I just think the local Imam would be reading something out and putting something up [referring to the college's blurb on its achievements]. Because I just think this is what people go for. They read it and they think, 'Wow!'

Y-Principal: It is mad - you'd have to be mad to go somewhere else [apart from the college].

Y-ASG: If you say that they think you've got a vested interest, but if you actually show them, they can't; this is the numbers. It's amazing to show them - we beat some of the other colleges.

X-ASG asserted in her interview that in her role she did not just agree with everything the SMT or other governors say but added the caveat that she would not challenge them in a negative way. Indeed, the observation statistics showed that she had a more balanced approach to challenge and support in governance, compared with the other two ASGs. Regarding Y-ASG's contributions, the Chair of the audit committee said, 'I've certainly seen support for particular views or initiatives or recommendations' but 'challenge - not as much.' In the case of Z-ASG, his position was that it was difficult to support or challenge SMTs. According to him, 'it puts you under pressure of not raising your head above the parapets' because sometimes SMTs' information to governors contradicted their information to the college staff. On the importance of support and challenge in governance, Ofsted (2012a) noted that at high performing colleges, governors could 'challenge managers vigorously' on the college's performance but suggested that if the relationships between governors including ASGs and the SMT were too close, problems with governance would start to emerge.

Satisficing decision-making could explain why one governor might challenge a decision while the other might not as in the case of X-College's SMT pay award decision in one of the corporation meetings. The external governor who challenged the award might have been underestimating X-SMT's performance while X-ASG, who supported it, might have been overestimating their performance; both cases suggest some satisficing behaviour because of their lack of complete knowledge about the matter (bounded rationality). The rationale for suggesting such boundedness is that at least X-ASG was not party to the original discussions as they had taken place in the remuneration committee, which X-ASG was excluded from; this was similar to the $22 \%$ of TGs excluded from some decision-making described in Earley and Creese (2001). Time was a bounded factor too in the final board discussion about SMT pay award, as revealed by another external governor, X-EXG4, in her interview. According to her, the award decision took about five minutes only, without much deliberation - an approach criticised by Avis $(2009,644)$ and dubbed as 'technicisation' of governance as much criticised in Hopkins' (2014) deliberative and democratic governance. 
Another example of satisficing behaviour in ASGs' decision-making was at Y-College, in the observed audit committee meeting, where Y-ASG supported the reappointment of financial auditors even though, as evident in the interviews, he had limited interest and involvement in the committee's matters. The bounded rationality (van Ees, Gabrielsson, and Huse 2009; Hendry 2005) of financial knowledge might have led to the satisficing support for the reappointment. Satisficing decision-making might also explain Z-ASG's suggestion and support for governors' observations of teachers' lessons during the annual strategy day. In fact, Z-ASG elaborated in the interview that his suggestion that governors observe lessons was not a good suggestion because, in hindsight, he could see that the timing would add unnecessary pressure on staff as the observations would take place during the college's assessment period - an extremely busy time for teachers.

\section{ASGs' role-specific activities}

ASGs' role-specific governance activities included the highly valued role of professional information giving using TLA knowledge and sometimes, academic subject-specific knowledge. In the questionnaires, the 3 ASGs revealed ASGs' frequent reliance on their professional expertise when contributing to governance meetings. Moreover, 92\% (32) of governors across the colleges were in agreement that ASGs helped the board to understand educational issues at their colleges. In the observed meetings, there was evidence of ASGs:

- using teachers' absenteeism statistics to support and approve stricter sickness policies;

- challenging an SMT's audit report highlighting its limited relevance to the curriculum;

- asking questions of SMT to enlighten external governors;

- highlighting IT equipment issues and their impact on the curriculum;

- describing the colleges' lesson observation and CPD arrangement for teachers;

- advising governors how to use their time during college visits, for instance, conducting governors' visits to lessons in a purposeful way.

One external governor captured the professional-information-giving role of an ASG by saying that their ASG was 'very good at providing context' in governance discussions around TLA matters. The study showed that ASGs' professional information may range from the highly valued knowledge such as an ASG's awareness of learners' educational needs to the comparatively less valued aspects such as ASGs management expertise (Figure 1).

College governors' valuing of ASGs' awareness of education contexts is in line with Masunga's (2014) finding that understanding of an FE education system is an important characteristic of an FE governor. This finding is comparable with New's (1993a) finding in school governance, where external governors doubted 


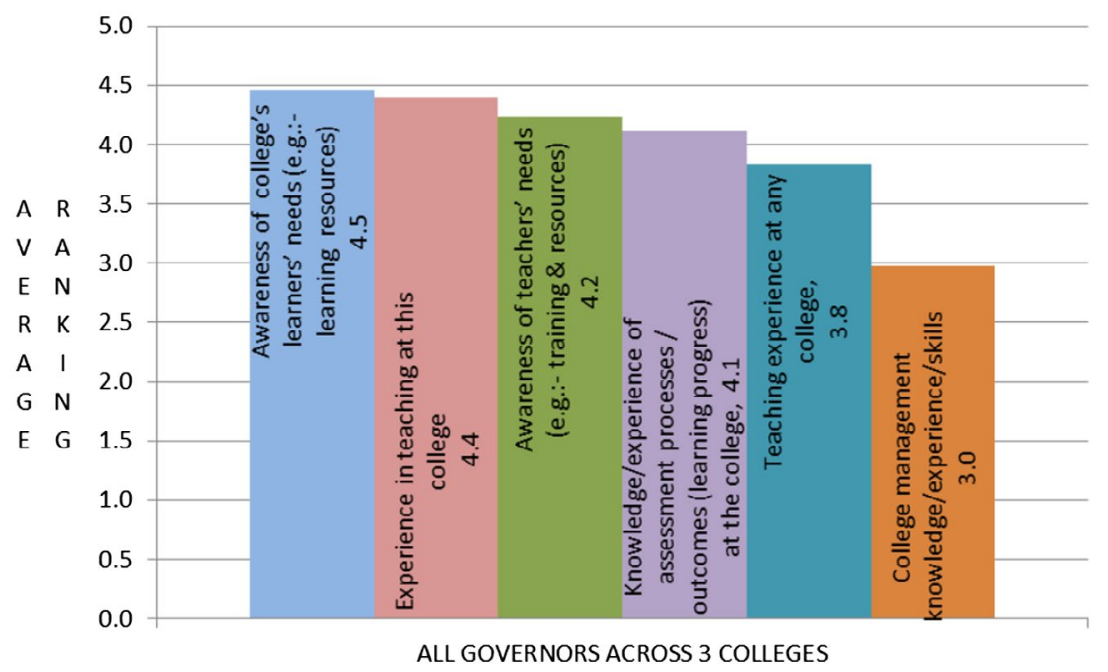

Figure 1. Q13 - ASGs' most valued experiences, knowledge and skills across the three colleges.

if TGs were competent enough when discussing non-educational matters such as management affairs. ASG at Y-College did not believe a teacher had to be a manager before he/she could become an ASG. An audit committee chair at one of the colleges did not believe the need for college managers assuming ASG roles and could not explain why the colleges in the study had curriculum managers fulfilling ASG roles. At the same time, what is not clear is if college SMTs influenced college managers' (rather than teachers') appointment to ASG roles. Any reimaging of ASG roles may need to consider this possibility. This issue also highlighted a need for future research to establish if non-managerial academic staff/teachers were less likely than managerial academic staff to assume ASG roles in FE colleges, and in the education sector in general.

In terms of ASGs' role in linking governance and TLA issues, to a limited extent ASGs appeared to participate in college visits such as graduation ceremonies, annual strategy days, as governors; some of which may be in their multiple roles as governors, managers and academic staff. The extent to which the 3 ASGs were able to distinguish these multiple roles during their visits differed from one another. X-ASG was very clear about her capacity in such visits unlike Y-ASG and Z-ASG. Comparing these findings with TGs at schools, in Earley and Creese's (2001) study, only 12 ( $5 \%$ of) TGs were observed to visit their schools regularly as governors.

Another finding in the current research was that, even though ASGs wished to act as link governors to support underperforming curriculum areas, unlike the external governors, ASGs' insiderness prevented them from playing such a role. This underlined the limited scope the ASGs were working in, where they were barred from contributing to the curriculum-related aspect of governance. It does raise questions as to how an ASG can perform their role using the full extent of their curriculum expertise as Hill (2012) has recommended, thus further laying down a case for a transformation of ASG roles in FE college governance. 
Finally, although representing staff views in governance was seen as a relevant role, the governance arrangements did not allow such a role. In practice, Y-ASG appeared to perform this function at an informal level while being uncertain he had the remit to do so. He believed that an ASG was in a good position to represent staff interests and bring issues to governance for the greater good of the college's education motives. To a limited extent, where it served the college's TLA priorities (for instance, IT equipment issues and staff absenteeism), X-ASG too was seen to raise staff issues in meetings. In line with the variance in opinion and practice regarding this role between X and Y ASGs, 64\% of X-College and 50\% of Y-College governors believed their ASGs attempted to represent staff interests. At Z-College, only $16 \%$ of the board believed Z-ASG was acting on behalf of the staff. This was reflected in his interview where he asserted that representing staff interest was neither practical nor a credible role. This ambivalence regarding staff representation is in line with the findings in studies at colleges (Lee 2000) and schools (Earley and Creese 2001).

There was evidence of other professional activities arising from ASGs' academic positions. For instance, X-ASG took a leading role in governor induction whereby she led the governors in college tours around curriculum areas giving governors a background for each area. In addition, her idea of inviting governors to the college's teacher-CPD events seemed to have materialised into a formal training schedule for future training for the governors. Similarly, Y-ASG took a leading role in organising student and community-related events in governance, although he was dissatisfied about being given a regular additional role in less satisfying activities such as mere opening of external project bid applications in the regular tender evaluations. As for Z-ASG, he used his subject-specific professional knowledge in computing to comment on the viability of digitising governance documents for use in meetings. The authors are of the view that through skills audits of ASGs, boards could identify areas beyond TLA matters for ASGs to contribute to in FE governance in an expanded and transformed ASG role.

\section{Understanding/confusion of the ASG role}

It appears that in the three boards, what the governors perceived as role uncertainty among ASGs did not always reflect the ASGs' views. At Y-College, the governors did not believe Y-ASG was uncertain but Y-ASG confessed that it was not clear to him what the role entailed. Similarly, Z-College governors believed Z-ASG was uncertain but Z-ASG displayed a good understanding of the role. At all three colleges, the uncertainty of the role could be among the wider college staff too, according to all 3 ASGs. Factors that cause the uncertainty, according to the comments in the surveys, included the ASG appointment process. College staff elect ASGs but ASGs are officially barred from representing staff interests, according to the governing instruments. In practice, this may be difficult to enforce because of the close proximity of ASGs with other teaching staff, and this was 
evident in Y-ASG's case. ASG training-related issues and a lack of clarity arising from an absence of ASG role specifications could also be factors related to the understanding of the role.

\section{Conceptualisation of ASG roles at the three FE colleges}

\section{The 3 RaPs framework of an ASG's role in FE governance}

In order to capture the themes of an ASG role emerging from the current study, a conceptual framework, named 'The 3 RaPs (Roles as Position/Perceived/Practice) Framework of an ASG Role', is proposed in Figure 2. The framework encompasses three facets of an ASG role in an FE college in England: roles-as-positions, rolesas-perceived and roles-as-practices, labelled $\mathrm{RaP} 1, \mathrm{RaP} 2$ and $\mathrm{RaP} 3$ respectively. Roles-as-positions (RaP1), introduced by James et al. (2007), relate to the concept of formal role in an organisation as discussed by Krantz and Maltz (1997). For the ASGs in the current case study, RaP1 (formal roles) refer to the responsibilities that applied to all governors in each college and specified in the colleges' instruments of governance. The current study showed that there were no role descriptions specific to ASGs - a situation similar to at least 38\% of colleges, in Hill's (2014) study. This study has shown that RaP1 at a college might incorporate ASGs' routine exclusion from certain committees such as remuneration committees due to RoDM (van Ees, Gabrielsson, and Huse 2009).

The second facet of an ASG role may be conceptualised as roles-as-perceived ( $\mathrm{RaP} 2$ ), a facet advanced as a product of the current research to link James et al.s (2007) two concepts of roles-as-position and roles-as-practices. Lee (2000)

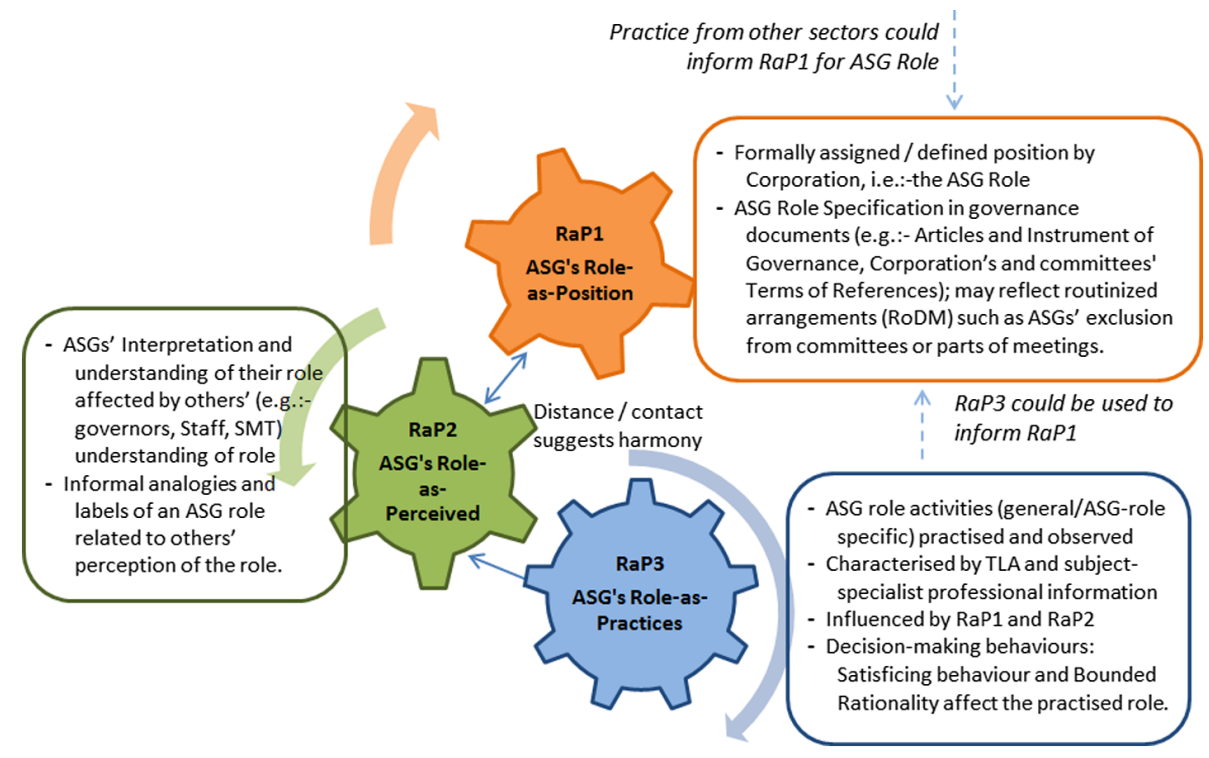

Figure 2. Conceptualisation of ASG role: the 3 RaPs framework. 
observed a discrepancy between how roles are understood and practised. This discrepancy could be conceptualised in terms of $\mathrm{RaP} 2$, a transitional phase between roles-as-positions ( $\mathrm{RaP} 1$ ) and roles-as-practices ( $\mathrm{RaP} 3)$, both of which correspond to the job specifications of the role and how the role is implemented by an ASG. $\mathrm{RaP} 2$ encompasses aspects that influence roles-as-practices and interpretations and understanding of RaP1 in formal documents.

RaP2 can also be characterised by stakeholders' expectations and perceptions of the role (Mullins 2004). At the three colleges in this study, there was evidence of the governors expecting ASGs to represent staffs' interests or views, which may potentially affect the actual role activities practised (RaP3; see below). Negative perceptions of an ASG's role by leaders (Lee 2000) or perceptions among governors as to the value of the role and what constitutes the role (Earley and Creese 2001; New 1993a) could both influence RaP3. At colleges Y and Z, the ASGs felt their role was not valued by the board and/or the SMT and this negative image could affect the role. Some may perceive and highlight ASGs as insiders within the college as evident in the current research. This too could affect room for ASGs' influence (Mace 1973), as it has been seen in the 3 ASGs' potential to participate in staff and SMTs' remuneration related issues; ASGs' ability to support/challenge SMTs in meetings; and their potential to contribute to governance.

Role understanding represented in $\mathrm{RaP} 2$ could also influence RaP3. In addition to the issue of the absence of ASG role specification (RaP1), factors that could influence ASG roles include how the role is interpreted by ASGs and others; role uncertainty associated with training; ASGs holding multiple roles at the colleges; and conflict between how ASGs and stakeholders such as staff see the role and what is expected of the role by governance arrangements.

The third and final gear in the framework in Figure 2 represents James et al's (2007) roles-as-practices (RaP3). In the current research, this concept encompasses the actual activities the ASGs were observed to be engaged in, in their governance role. The current study found that statutory activities formed the bulk of ASGs' RaP3 activities. Key observations of the nature of the RaP3 activities included:

- ASGs consulting SMT or corporation chair informally in governance matters;

- some tendency for ASGs to consider the community's needs but role affected by limited expertise which may correspond to van Ees, Gabrielsson, and Huse's (2009) organisational reality of bounded rationality;

- generally more support from ASGs for SMT than challenging them; ASGs' contributions to decision-making may be affected by their satisficing behaviour where the most immediate need may be considered rather than considering issues thoroughly; 
- contributions in meetings using TLA-specific expertise; and sometimes other expertise derived from academic subject specialism, community or student links;

- ASGs tended to be members of curriculum/quality committees but mainly barred from remuneration and search committees; this pattern and restriction shaped and limited their governance roles and activities, despite their potential to contribute to non-TLA matters in a reimagined ASG role;

- some evidence of ASGs representing staff views and interests; and

- ASGs visiting college areas to conduct governing activities but no evidence of them acting as link governors for specific curriculum areas.

In terms of symmetry between ASG role types, $\mathrm{RaP} 1$ to $\mathrm{RaP} 3$, in reality there may be discrepancies between the role aspects for a given ASG. This is denoted in Figure 2 by the arrows showing distance/contact between the gears containing each of the types of roles. When the gears are not in contact, they represent a situation where ASG roles may have room for improvement for effective governance. For instance, it was noted that college governors regarded 'meeting the needs of the community' as a highly relevant activity for ASGs (RaP2). In practice, however, this function was observed only in $26 \%$ of the 3 ASGs' contributions (RaP3). Similarly, at all three colleges, governors did not recognise ASGs' management experience or managerial status as relevant or useful to the role ( $\mathrm{RaP} 2)$, but in practice all 3 ASGs were managers (RaP3). In addition, ASGs' potential to represent staff views was recognised as a valued aspect ( $\mathrm{RaP} 2)$ but the instruments of governance $(\mathrm{RaP} 1)$ at the colleges did not allow such a role. Another example is that, at Y-College, governors felt that the ASG had a clear understanding of the role ( $\mathrm{RaP} 2$ ) but Y-ASG admitted to his uncertainty of the role and at times engaged in activities that represented staff interests at an informal level (RaP3).

In optimal governance, the $3 \mathrm{RaP}$ 'gears' would be in harmony and contain information that complements one another, instead of contradicting concepts of the ASG role. The harmony may be helped through training for governors on ASG roles; the presence of ASGs' role specifications in articles and instruments of governance, which are informed by regular evaluation of RaP3 activities; and using knowledge and expertise shared by governance collaborators in other sectors such as schools, universities and corporate governance. In the framework, such information is represented by the dashed arrows. The authors believe in a reformed role, and such a harmonious model of ASG role would address Sallis's (2006) description of the TG/ASG role as the most difficult role in an educational institution's governing board.

\section{Conclusion}

The findings about ASG roles and the ASG role framework in the study could be applied in governance research in other colleges, or with modification, to other 
educational contexts. The research suggests that there is much room to transform ASG roles and, as a result, for ASGs to play a significantly fuller role in educational governance. In order to facilitate this, several recommendations for governance practitioners can be identified from the case study:

(1) FE corporations should introduce specific role descriptions for ASG roles in the articles of governance in order to aid role understanding.

(2) In reimagining ASG roles and to address ASGs' insiderness, it may be worth while considering Y-ASG's and Z-ASG's idea of discussing at least some governance issues in SMTs' absence. This may encourage more contributions from ASGs, especially the necessary challenge to SMT's proposals and plans and independent support from them, adding more autonomy to ASGs' statutory roles in FE governance.

(3) Another way of addressing ASGs' insiderness is by providing them with opportunities to assume ASG governorships at other FE colleges, as opposed to at their own college.

(4) FE governors' training data could be included in national databases, such as AoC's (2014) surveys, in order to publicise vital profile and governance efficiency-related information. This could help boards focus more on responsibility for improving their practice through governor training - a characteristic of effective boards (Bartlett 2008).

(5) A research methodological recommendation for future researchers in ASG roles is to observe ASGs on corporations' strategy and/or training days, and in ASGs' special governance tasks, in order to gather deeper and richer evidence related to ASG-role-specific activities. Through such research, the sector will be able to assess the impact on FE governance from a reimagined ASG role.

From the multi-site case study, and based on the opinion of various governors, it is clear that ASGs are unique in their capacity to bring the shop-floor TLA perspective to governance, as no other governors are in a position to present this perspective with the immediacy an ASG can. Within a reimagined model of ASG roles in governance, where consideration is given to the three aspects of the roles put forward in this paper (Role-as-Position, Role-as-Perceived and Roleas-Practices), it may be easier to see how the ASGs' potential to contribute to FE governance can be fully exploited.

\section{Disclosure statement}

There is no conflict of interest between the colleges researched in the study and the authors or the supporting institutes.

\section{Funding}

This research was supported by University of Warwick and City College Coventry. 


\section{Notes on contributors}

Abdulla Sodiq has a Doctorate in Education from the University of Warwick and has worked as an English Language (ESOL/EFL) Lecturer since 1998. He currently works at City College Coventry, UK and is also a co-founder of Maldives Research, a think tank researching public policy in the Maldives. Twitter: @DrAbdullaSodiq

Ian Abbott is Associate Professor and Director at Centre for Education Studies, University of Warwick. Prior to higher education, he worked in schools and colleges in senior leadership roles for a number of years. Email: i.d.abbott@warwick.ac.uk

\section{ORCID}

Abdulla Sodiq (D) http://orcid.org/0000-0002-8488-7467

\section{References}

AoC. 2013. Creating Excellencein College Governance. London: AoC.

AoC. 2014. The Composition of English Further Education Corporations and College Governance Frameworks: A Report on the Association of College's Survey of FE Corporations. Accessed August 1, 2014. https://www.aoc.co.uk/sites/default/files/Board\%20Composition\%20 Survey\%202013_0.pdf

Avis, J. 2009. "Further Education in England: The New Localism, Systems Theory and Governance." Journal of Education Policy 24: 633-648. December 22, 2011. doi:10.1080/02680930903125137.

Bartlett, D. 2008. “Governance and Accountability." Independence 33 (2): 52-53.

Brennan, N. M., C. Kirwan, and J. Redmond. 2016. "Accountability Processes in Boardrooms: A Conceptual Model of Manager-Non-Executive Director Information Asymmetry." Accounting, Auditing \& Accountability Journal 29 (1): 135-164. doi:10.2139/ssrn.2343235.

Bush, T. 2007. "Authenticity in Research - Reliability, Validity and Triangulation." In Research Methods in Educational Leadership and Management, edited by Ann R. J. Briggs and M. Coleman, 91-105. London: Sage.

Carver, J., and M. Carver. 2013. Policy Governance FAQ - the Model. Accessed February 25, 2013. http://www.carvergovernance.com/faq1.htm\#hierarchical

Chapman, R., D. Collinson, and M. Collinson. 2009. "Giving Voice to College Leaders: The Journey towards Self-Regulation?” In Researching Self-Regulation in FE Colleges, edited by D. Collinson, Vol. 12, 7-26. Coventry: LSIS.

Clow, R. 2005. "Just Teachers: The Work Carried out by Full-Time Further Education Teachers." Research in Post-Compulsory Education 10 (1): 63-82. doi:10.1080/13596740500200193.

Cornforth, C. J., and C. Edwards. 1998. Good Governance: Developing Effective BoardManagement Relations in Public and Voluntary Organizations. London, UK: CIMA Publishing.

Cornforth, C., and C. Edwards. 1999. "Board Roles in the Strategic Management of Non-Profit Organisations: Theory and Practic." Corporate Governance: An International Review 7 (4): 346.

Earley, P., and M. Creese. 2001. “The Uncertain Teacher Governor: Seeking a Role?” Research Papers in Education 16 (4): 323-335.

van Ees, H., J. Gabrielsson, and M. Huse. 2009. "Toward a Behavioral Theory of Boards and Corporate Governance." Corporate Governance: An International Review 17 (3): 307-319. 
Fogelman, K., and C. Comber. 2007. "Surveys and Sampling." In Research Methods in Educational Leadership and Management, edited by Ann R. J. Briggs and M. Coleman, 125-141. London: Sage.

Fuller, K., S. Parsons, N. MacNab, and H. Thomas. 2013. "How Far is Leadership Distributed in Extended Services Provision?” Educational Management Administration \& Leadership 41 (5): 598-619.

Gleeson, D., I. Abbott, and R. Hill. 2009. Creative Governance in Further Education: The Art of the Possible?. London: LSIS.

Gleeson, D., I. Abbott, and R. Hill. 2010. "Governing the Governors: A Case Study of College Governance in English Further Education.” British Educational Research Journal 37 (5): 781-796.

Hendry, J. 2005. "Beyond Self-Interest: Agency Theory and the Board in a Satisficing World." British Journal of Management 16: S55-S63. doi:10.1111/j.1467-8551.2005.00447.x.

Hill, R. 2012. "Understanding the Staff Governor as a Member of a Further Education College Governing Body." Coventry: LSIS. http://www.wolvcoll.ac.uk/wp-content/uploads/2014/06/ Role-of-the-Staff-Governor-LSIS-Guide.pdf.

Hill, R. 2014. "Trends in Governance in Further Education." Local Government Studies 40 (6): 972-985.

Hill, R., Y. Downs, and J. E. Drake. 2012. Getting Ready for New Governance Freedoms: A Survey of Further Education College Governance. University of Huddersfield.

HMSO. 2011. Education Act 2011 (c.21;s.49). London: HMSO.

Hopkins, N. 2014. "College Governance and Deliberative Democracy." In Citizenship and Democracy in Further and Adult Education. Springer Netherlands. Accessed June 1, 2013. https://doi.org/10.1007/978-94-007-7229-8_7

James, C. R., M. Connolly, G. Dunning, and T. Elliott. 2007. "Systemic Leadership for Schools.” Educational Management Administration and Leadership 35 (4): 573-588.

James, C., J. Jones, M. Connolly, S. Brammer, M. Fertig, and J. James. 2012. "The Role of the Chair of the School Governing Body in England.” School Leadership \& Management 32 (1): 3-19.

Krantz, J., and M. Maltz. 1997. "A Framework for Consulting to Organizational Role." Consulting Psychology Journal: Practice and Research 49 (2): 137.

Lea, J. 2005. 'Getting Your Lines Right': Scripted Communication in Post-Compulsory Education." In The RoutledgeFalmer Guide to Key Debates in Education, edited by Dennis Hayes, 157-163. London: Taylor \& Francis.

Lee, B. 2000. "The Governance Role and Activity in Colleges of Further Education." PhD Thesis, University of Nottingham.

LSIS. 2012. "Challenges for FE College Governance and Priorities for Development: An LSIS Perspective." https://www.gloscol.ac.uk/media/20919/ChallengesForFECollegeGovernance. pdf.

Mace, M. L. 1973. “The President and the Board of Directors.” McKinsey Quarterly 4: 20-34.

MacNeill, N., S. Silcox, and R. F. Cavanagh. 2003. “Pedagogic Principal Leadership." Management in Education 17 (4): 14-17.

Masunga, R. 2014. "Further Education Governance: The Role of Governors in Further Education (FE) College Improvement." Ed.D., School of Education, University of Birmingham.

Matthews, J., M. Snell, and R. Chapman. 2011. Case Studies of Governance Arrangements in the Further Education Sector (UK, Australia, Spain, USA). Coventry, Great Britain: LSIS.

McNay, I. 2002. "Governance and Decision-Making in Smaller Colleges." Higher Education Quarterly 56 (3): 303-315.

Mullins, L. J. 2004. Management and Organisational Behaviour. Harlow: Financial Times Prentice Hall. 
New, S. 1993a. "Governing Bodies and the Teacher Voice." Journal of Teacher Development 2 (2): $70-80$.

New, S. J. 1993b. “The Token Teacher: Representations of Professional Educators in School Governing Bodies." International Studies in Sociology of Education 3 (1): 69-89.

Ofsted. 2012a. How Colleges Improve [Online Report]. HMSO. www.ofsted.gov.uk/ resources/120166.

Ofsted. 2012b. Outstanding Providers List: 1993/94 - 2011/12. London: Ofsted.

Patterson, J. A., and C. Marshall. 2014. "Making Sense of Policy Paradoxes: A Case Study of Teacher Leadership.” Jsl 11-N5 (11): 372.

Qualtrics. 2002. Qualtrix Research Suite [online software]. Qualtrics Labs. http://www.qualtrics. $\mathrm{com} /$.

Sallis, J. 2006. Staff Governors: Your Own Guide. Abingdon: Adamson Publishing.

Schofield, A., J. Matthews, and S. Shaw. 2009. A Review of Governance and Strategic Leadership in English Further Education: The Future Challenges Facing Governance and Strategic Leadership in FE. London: LSIS.

Shattock, M. 2002. "Re-Balancing Modern Concepts of University Governance." Higher Education Quarterly 56 (Article): 235-244.

Sodiq, A. 2012. "The Composition of Governing Bodies: A Case Study of a College in England." http://wrap.warwick.ac.uk/49208/.

Stoker, G. 2004. "New Localism, Participation and Networked Community Governance." http:// web.iaincirebon.ac.id/ebook/moon/LocalMatters/New\%20Localisme\%20Politics.pdf.

Taylor, F. 1983. Accountability in Education: The Role of Elected Parent and Teacher Governors of Schools, and Their Relationship with Their Constituencies. Chelmsford: Centre for Institutional Studies, Anglian Regional Management Centre.

Wilkins, A. 2014. "Main Presentation: Findings from the Economic and Social Research Council (ESRC) Funded Project, SASE (School Accountability and Stakeholder Education, 2012-2015)." Paper presented at the Governing Schools Conference, Governing Schools: Professional Power and the Changing Responsibilities of School Governors, October 23. University of Roehampton.

Zajac, E. J., and J. D. Westphal. 1996. "Director Reputation, CEO/Board Power, and the Dynamics of Board Interlocks." Paper read at Academy of Management Proceedings. New York: Cornell University. 